International Journal of Cloud Applications and Computing, Vol. 2, No. 1, 2012

\title{
Business Integration as a Service
}

\author{
Victor Chang ${ }^{1,2}$, Robert John Walters ${ }^{1}$, Gary Brian Wills ${ }^{1}$, \\ 1. School of Electronics and Computer Science, University of Southampton, Southampton, UK. \\ 2. Business School, University of Greenwich, London, UK. \\ vic1e09@ecs.soton.ac.uk
}

\begin{abstract}
This paper presents Business Integration as a Service (BIaS) which enables connections between services operating in the Cloud. BIaS integrates different services and business activities to achieve a streamline process. We illustrate this integration using two services; Return on Investment (ROI) Measurement as a Service (RMaaS) and Risk Analysis as a Service (RAaaS) in two case studies at the University of Southampton and Vodafone/Apple. The University of Southampton case study demonstrates the cost-savings and the risk analysis achieved, so two services can work as a single service. The Vodafone/Apple case study illustrates statistical analysis and 3D Visualisation of expected revenue and associated risk. These two cases confirm the benefits of BIaS adoption, including cost reduction and improvements in efficiency and risk analysis. Implementation of BIaS in other organisations is also discussed. Important data arising from the integration of RMaaS and RAaaS are useful for management of University of Southampton and potential and current investors for Vodafone/Apple.
\end{abstract}

Keywords: Business Integration as a Service (BIaS); ROI Measurement as a Service (RMaaS); Risk Analysis as a Service (RAaaS); BIaS Case Studies.

\section{Introduction}

Cloud Computing is transforming the way many organisations work and offers added values for operation management and service computing. Researchers have demonstrated the positive impacts it can offer for business engineering and service level management (Amburst et al., 2009; Brandic et al., 2009; Buyya et al, 2009). Amburst et al (2009) identified cost reduction in IT services from using Cloud Computing. They also presented their Cloud Computing economics and ten major challenges for Cloud Computing. They emphasise a shift of risk from maintaining data centres and the capital costs of running them to the loss of data while managing Clouds.. Buyya et al. (2009) assert that Cloud Computing offers billing-based Service Level Agreements (SLA) which can be used for operational management offering cost-savings and streamlining business activities and processes. In addition, Cloud Computing offers a variety of other benefits including agility, resource consolidation, business opportunities and green IT (Foster et al; 2008; Weinhart et al. 2009; Schubert, Jeffery and Neidecker-Lutz, 2010; Chang et al., 2011 a; 2011 d; 2011 e; Kagermann, 2011).

Computing Clouds are commonly classified into Public Clouds, Private Clouds and Hybrid Clouds (Ahronovitz et al., 2010; Boss et al., 2007; Sun Microsystems, 2009). The type of Cloud an organisation adopts will depend on its needs and the volumes and types of services and data they plan to have and use.

\subsection{Business Integration Literature}

In their pioneering paper on business integration, Krippaehne et al. (1992) proposed a strategy matrix for vertical integration to present strategies, goals and factors influencing successful business integration. Business Integration (BI) in Information Technology started from the concept the Business-to-Business (B2B) e-commerce which provides an architecture for integration of different activities and technologies. Bhaskaran et al. (2001) describe their B2B architecture which is divided by into technological frameworks. They explain each component and how they co-operate. Trastour et al. (2003) propose their NILE System to demonstrate Business Integration and explain how XML schema and RDF work together in their system. Vojdani (2003) identifies six application groups for utility companies in his business integration platform and explains how these components work. He uses Business Process Management (BPM) to present Business Integration and Collaboration. Vinosk (2005) proposes Java Business Integration (JBI) by the use of enterprise application integration (EAI) offered by Java and Service Orient Architecture (SOA). Iyengar et al. (2007) introduce BI using IBM WebSphere Business Integration (WBI) technology which consists of Service Component Architecture (SCA), basic business processes and workflows. They use business process management (BPM), SOA BI scenarios, architecture, patterns and WS-BPEL related 
technologies to demonstrate BI. Rebstock et al. (2008) demonstrate ontology and semantic-based architecture and deployment on BI and explain their rationale and business cases. Chrisdutas (2008) consolidates the proposal from Vinosk (2005) and presents SOA Java BI. He explains the operation of JBI including each individual component and the interactions between different JBI containers. This work is based on SOA architecture which either focuses on JBI or semantic approaches.

Papazoglou and van den Heuvel (2011) present two models related to BI. The first is cloud delivery model in which they explain interactions between virtualised applications, clients and a stack comprising IaaS, PaaS and SaaS suitable for Business Process as a Service (BPaaS). Their second model, the blueprint model, is proposed to allow BPaaS or SaaS applications to run dynamically on virtualised clouds to enable service virtualisation. There are three components to the model: (i) blueprint definition language (BDL); (ii) blueprint constrain language (BCL) and (iii) blueprint manipulation language (BML). They also explain an architectural scenario showing how blueprint support for the cloud service life cycle can work. However, their approach is at the system design level without details of implementation, testing or use cases. Moran et al (2011) present Rule Interchange Format (RIF), RIF Mapping, RIFexpressed rules and a use case. They explain how semantic-based integration can be achieved on IaaS level. However, their notion of BI is not the same as ours for the following reasons. Firstly, their integration is based on data exchange between different VMs to update RIF status in the Cloud. Secondly, it is not clear whether their use case only works for IaaS, although they seem to imply this approach may work on PaaS and SaaS level in future work. Ring et al. (2009) explain the integration of Grid and Cloud systems using two approaches. Their first is to redesign architectures of different Grid systems and their second is to implement interoperability, which includes reimplementations of Unicore 6, Globus 4, GLite, OMII Grid and so on which also contain other components such as security, standardisation and service discovery. However, that is interoperability and includes re-implementations of existing systems and components. That method is suitable for Grid but not necessarily for Cloud due to the following reasons:

- Use of Virtual Machines (VMs) is not a pre-requisite

- There is no pay-as-you-go characteristic

- It does not have a good scalability like what Cloud does.

This paper describes our own flavour of Business Integration as a Service (BIaS) and case studies confirming its benefits for organisations adopting cloud. In our demonstration of integration, we are connecting two different services to allow a user request to be performed as thought they were one service rather than two separate services. The structure for this paper is as follows. Section 2 gives an overview and motivation for proposing BIaS. Section 3 explains system design and architecture of integrating two services: ROI Measurement as a Service (RMaaS) and Risk Analysis of Services (RAaaS). Section 4 and 5 show case studies of BIaS. Section 4 describes a case study of University of Southampton about how to integrate RMaaS and RAaaS and its results. Section 5 describes the Vodafone/Apple case study with its RMaaS and RAaaS results and analysis. Section 6 presents Discussion and Section 7 sums up with some conclusions and outlines future work.

\section{Business Integration as a Service (Blas) Overview}

Integrating different business activities together into the same environment can improve efficiency, reduce costs and improve collaboration. This is particularly true for big organisations with many locations and departments deploying Cloud Computing and for businesses to achieve long-term sustainability using Business Process as a Service (BPaaS) to improve business connectivity and streamline the essential process. Höing et al. (2009) use Grid Computing and WS-BPEL to demonstrate BPaaS as an Orchestration as a Service Infrastructure. Norta (2010) used his service hub system architecture to explain how BPaaS works. However, BPaaS is process dependent and focused on a particular process at a time, and is not necessarily connect different business activities together.

There are Cloud economics and business model papers where there are several interesting challenges to be addressed. Firstly, all cloud business models and frameworks proposed by several leading researchers are either qualitative (Briscoe and Marinos, 2009; Chou, 2009; Weinhardt et al., 2009; Schubert, Jeffery and Neidecker-Lutz, 2010) or quantitative (Brandic et al., 2009; Buyya et al., 2009; Armbrust et al., 2009). Qualitative research focuses on defining the right strategies, business model classifications, business requirement collection and customer requirement supported by case studies and user feedback. Quantitative research focuses on billing and pay as you go models, Return on Investment (ROI) calculations and validation supported by experiments or simulations. Each business model, either qualitative or quantitative, is self-contained. Each contains a series of proven hypotheses and methods supported by case studies and/or experimental results. Generally there is no interaction or collaborative work between different models and services. This means there is no connection between quantitative and qualitativebased Cloud services. However, this is essential for Business Integration as a Service (BIaS), as the business 
requirements collected by qualitative services need to transform to quantitative Cloud analysis. Traditionally, many organisations employ business analysts to bridge the gap between quantitative and qualitative services/requirements. Similarly, there are few connections between different quantitative services such as integration between cost-saving services and risk analysis services. Although vendors' lock-in is a technical challenge (Ambrust et al., 2009; Papazoglou and van den Heuvel; 2011), integration of different services is another challenge. Here is an example. An organisation needs to use Cloud service provider A for measuring and analysing business performance. They use Cloud service provider B for identifying and quantifying risk analysis. Both services are managed and offered by different providers and have different requirements and technical solutions. Costs are nearly double than an integrated service that can provide both services. This motivates us to propose Business Integration as a Service (BIaS). The objective is to allow two or more activities/services at any level (IaaS, PaaS, SaaS) that are traditionally separate services to integrate as a single service. This saves costs, improves efficiency, serves more purposes and provides more added values for businesses.

\subsection{What motivates us to propose Business Integration as a Service (BIaS)}

Often each Cloud service is independent. Some even involve multiple steps. Each service request has to be handled separately and there is a lack of communication between services leading to the following problems:

- There is no communication between services. Each time two types of service requests and activities have to done at different periods of time.

- Creation of additional work and cost. It also costs more to pay two service providers.

- It is difficult to check consistency of computational results from different service providers.

Integration between different types of services is required and all services need to be carried out within the same framework without communications and technological barriers (such as BPEL to BPMN). This motivates us to propose and demonstrate Business Integration as a Service (BIaS), which aims to offer the following:

- To allow two or more different services to work together where traditionally each service would be separate from the others.

- To permit the outcome of one service to be used as input for another; integrating two or more services into one.

Details are presented between Section 3, 4 and 5.

\section{System Design and Architecture for BlaS}

We develop two different Cloud services and their descriptions are as follows:

- $\quad$ ROI Measurement as a Service (RMaaS): The aim is to measure Cloud business performance. It starts as a PaaS-based statistical service to compute and analyse key statistical data. It then gets to the second step of RMaaS, which is a SaaS-based service to present key analysis in a 3D Visualisation. The third step of RMaaS is a Quality Assurance (QA) SaaS-based service to ensures that the 3D data has a high quality and to further analyse the implications of data.

- Risk Analysis as a Service (RAaaS): The purpose of this service is to calculate risks and evaluate its impact on an organisation. RaaaS starts with a SaaS-based risk analysis offered by Variance-Gamma Process (VGP) which reduces inconsistencies and errors and calculates the risk pricing. It then moves to second step of RaaS, another SaaS-based service based on Least Square Method (LSM) that computes high-performing simulations and to calculate the most expected risk pricing and its most likely range. Risk pricing means the expected risks involved and can be quantified as a numeric number (used in financial options: European or American) or a percentage (such as presenting percentage of loss) (Hull, 2009; Waters, 2008). If a risk pricing is $20 \%$, it means it will cause $20 \%$ of undesirable impacts such as loss of revenues.

We first present how each service works and then how the two services can work together in the BIaS framework..

\subsection{System Design and Architecture}

BIaS provides linkage between different types of services which in turn leads to efficiency improvement and time reduction in business processes. Services in BIaS can work within the same framework without barriers in communications by connecting all services and ensuring (interim) service output formats are acceptable input for the next. BIaS can offer services and connect services together to save businesses time and resources for analysis. It also allows them to compute complex models while keeping easy to use concepts and features (Chang et al., $2011 \mathrm{~d}$ ). 
Our System Design and Architecture is similar to Papazoglou and van den Heuvel's (2011) cloud delivery model except we avoid using a new language. A number of technologies is used for each step of the service. The major advantage being that each step has a preference for certain technologies or platforms due to its functionality. For example, a statistical computing service favours statistical languages or packages. Figure 1 shows System Design and Architecture, the structure of each service, how different services are connected to each other and how data is exchanged between different virtualised layers.

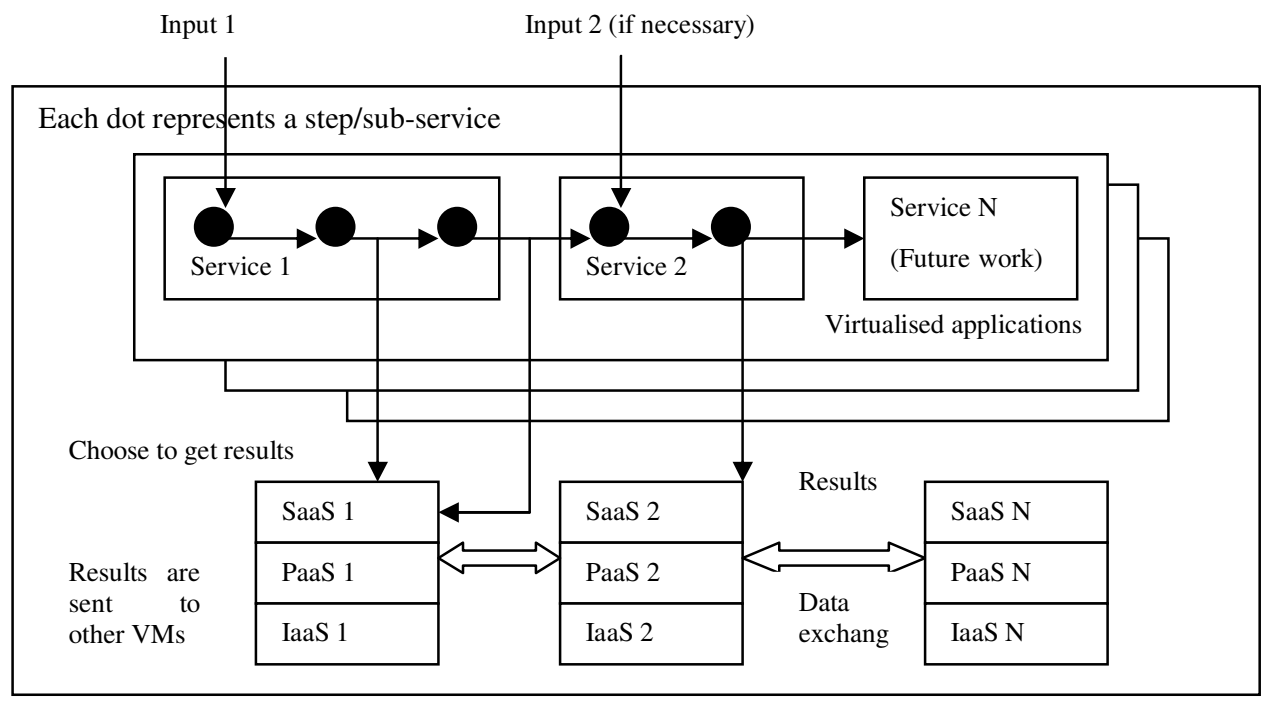

Figure 1: System Design and Architecture for BIaS in Southampton Private Cloud

Service 1 is RMaaS which includes three steps. It requires completion of at least the first two steps before presenting results. Each step in RMaaS is considered as a sub-service as follows:

1. Statistical service: This computes Cloud business performance with key statistical data offered by SAS, a statistical program.

2. Visualisation service: Results from statistical service pass onto this step which presents key data using 3D Visualisation enabled by Mathematica. Completion of this step is the minimum requirement for RMaaS.

3. Quality Assurance service: This is an additional step required when connecting to another service. It ensures data quality and performs further analysis of the implications of data.

Results are saved in text formats readable by each service and then passed onto the next step. Service 2 is RAaaS which is itself comprised of two steps. Results from the last step of RMaaS are passed onto the first step of RaaaS. Similar to RMaaS, each step in RaaaS is a sub-service and the two steps are:

1. VGP risk analysis service: This reduces inconsistencies and errors and calculates the risk pricing. It computes results showing frequency of occurrence and risk pricing.

2. LSM risk analysis service: This computes high-performing simulations and calculates the most likely risk pricing and its upper and lower bounds.

Integrating RMaaS and RAssS requires the following:

- Results from the end of RAaaS and the end of each step need to be saved as text and passed to the next step, allowing results from each service to be passed onto the next.

- Use requests (ROI measurement and risk analysis) are completed in one rather than as two separate services.

The experiments are performed using a private cloud located in Southampton, distributed between two sites; two high performance servers with multiple VMs located at University of Southampton and two clusters of eight servers with VMs located at the lead author's home. All are connected to form a private cloud. 


\subsection{How to validate BIaS and Hybrid Case Study}

Projects and services implemented by BIaS require verification which needs a number of techniques and focuses. A case study approach is the primary method of verifying BIaS. This is relevant to our framework to help organisations to achieve good Cloud design, deployment and services. In each organisational case study, experiments are used for validation. Each experiment consists of a number of simulations and models which are often packaged as a SaaS.

Table 1: An overview of verifying BIaS

\begin{tabular}{|c|c|c|c|c|}
\hline Organisations & BIaS focus & $\begin{array}{l}\text { Method with } \\
\text { qualitative } \\
\text { focus }\end{array}$ & $\begin{array}{l}\text { Method with } \\
\text { quantitative focus }\end{array}$ & Remark \\
\hline $\begin{array}{lr}\text { University } & \text { of } \\
\text { Southampton, See } \\
\text { Sections } 4\end{array}$ & $\begin{array}{l}\text { To demonstrate how } \\
\text { RMaaS and RAaaS } \\
\text { can work together }\end{array}$ & $\begin{array}{l}\text { Hybrid Case } \\
\text { Study }\end{array}$ & $\begin{array}{l}\text { Experiments, } \\
\text { simulations and } \\
\text { modelling } \\
\text { Hybrid Case Study }\end{array}$ & $\begin{array}{l}\text { It computes relevant } \\
\text { analysis to help stake } \\
\text { holders making right } \\
\text { decisions. }\end{array}$ \\
\hline $\begin{array}{l}\text { Vodafone/Apple, } \\
\text { See Section } 5 .\end{array}$ & $\begin{array}{l}\text { To demonstrate how } \\
\text { RMaaS and RAaaS } \\
\text { can work together }\end{array}$ & $\begin{array}{l}\text { Hybrid Case } \\
\text { Study }\end{array}$ & $\begin{array}{l}\text { Experiments, } \\
\text { simulations and } \\
\text { modelling } \\
\text { Hybrid Case Study }\end{array}$ & $\begin{array}{l}\text { It provides a series of } \\
\text { good quality analysis } \\
\text { and to understand the } \\
\text { extent of success of } \\
\text { their strategies. }\end{array}$ \\
\hline
\end{tabular}

A hybrid case study is an approach that adopts both qualitative and quantitative methods. Kaplan and Duchon (1988) are the pioneers of this type of approach. They explain what led them to integrate both methods and how to use the integrated approach which is particularly useful when analysing performance of clouds in businesses that use organisational data or computational analysis that requires more details from users. Methods include surveys and interviews from qualitative methods, modelling, simulations and experiments from quantitative methods.

Each case study uses simulation and modelling which are mainly done by MATLAB or Mathematica as described in Financial Clouds Review (Chang et al., 2011 a). A challenge is to get a platform to integrate different simulations together.

\section{BlaS Case Study at the University of Southampton}

The objective is to present the case study of University of Southampton, where the current status and results of BIaS have been reviewed. This includes at least three different departments: School of Electronics and Computer Science (ECS), i-Solution Group (providing ICT services) and Corporate Planning. This case study describes how different services work together such as ROI Measurement as a Service (RMaaS) and Risk Analysis as a Service (RAaaS) and demonstration of how RMaaS and RAaaS can work together as an integrated solution.

\subsection{ROI Measurement as a services (RMaaS)}

CAPM can be modelled by statistical languages, of which SAS is more suitable than others since it can compute more in-depth analysis (Chang et al., 2010 b; 2011 b; 2011 c; 2011 e). The objective of ROI Measurement as a Service (RMaaS) is to measure cloud business performance, so that the organisation can be aware of their ROI and can help stake-holders to make the right business decisions. This involves with two mini steps. The first step is a PaaS service analysing business performance by computational statistics and the second step is a SaaS which involves computing statistics and presenting them into 3D Visualisation.

\subsubsection{D Visualisation within RMaaS}

RMaaS is a PaaS to allow Cloud architect to calculate business performance. SAS code is written on Cloud to predict the Risk Premiums of an organisation, such as ECS versus the Market (expected values). The data collected covers November 2007 to July 2010. The data is carefully calculated and examined with data consistency and coding algorithms.

The collected data covers November 2007 to July 2010. CAPM can be modelled by statistical languages, in which SAS is a statistical computing language more suitable than others since it can compute more in-depth analysis (Chang et al., 2010 b). SAS code is written to predict the Risk Premiums of an organisation, ECS versus the Market (expected values). The data is carefully calculated and examined with data consistency and coding algorithms. 
Thirty two months of in-depth data can best represent sustainability from the initial phase to establishment. The SAS program for the CAPM is coded to plot required data with a suitable regression method. Table 2 shows a summary of this statistical computing.

Table 2: Regression summary of ECS cost-saving

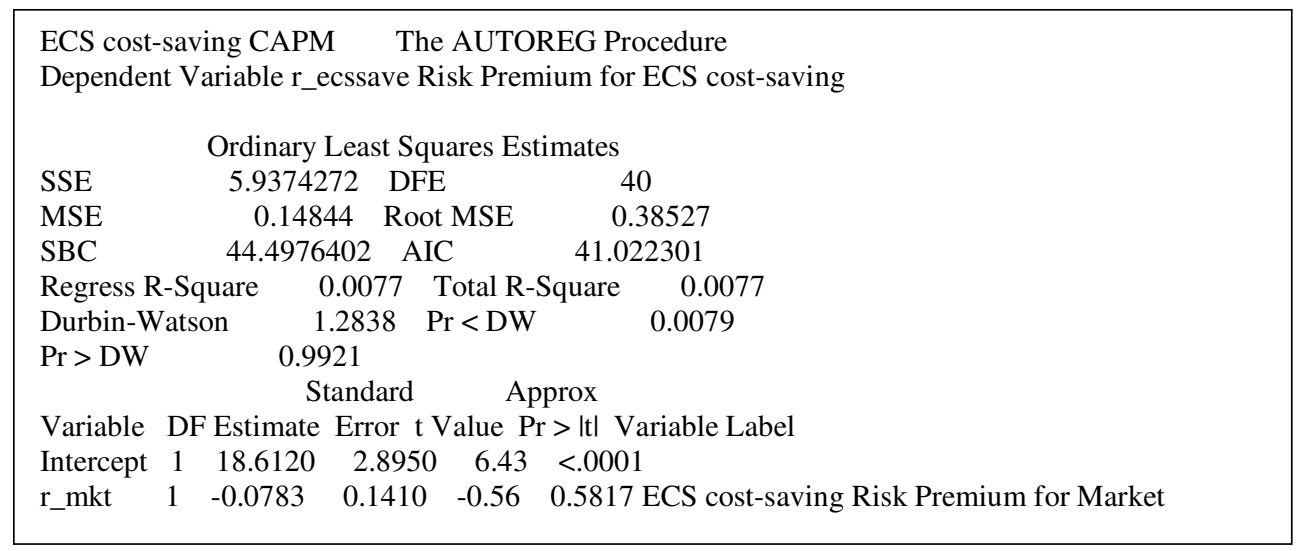

Market is referred as the Expected values. The risk-free rate in this case study means the minimum operational costs in staffing and IT resources. ECS confirms their risk-free rate is reliable, and thus the risk premium is the difference between the expected values and risk-free rate. Table 2 presents the result of auto linear regression summary with Ordinary Least Squares used (OLS), which calculates accurate estimates. The lower the Mean Square Error, the more accurate the regression result. Durbin-Watson is also used to test auto-regression and accuracy of the output. CAPM statistics then computes the actual and predicted values of analysis in linear regression. The predicted values can be used as an expected result in the next phase.

\subsubsection{D Visualisation within ROI Measurement Services}

Further statistical analysis can be computed. However, this often requires those with relevant training to perform such tasks. Our major contribution in this project is to present complex statistical analysis using 3D Visualisation, which is a SaaS service enabled by Mathematica. The benefit is to ensure no data is missed for analysis, and also those without advanced statistical backgrounds can understand. This is useful for many decision-makers and directors who need to know business analytic results quickly but need not spend too much time to understand them.

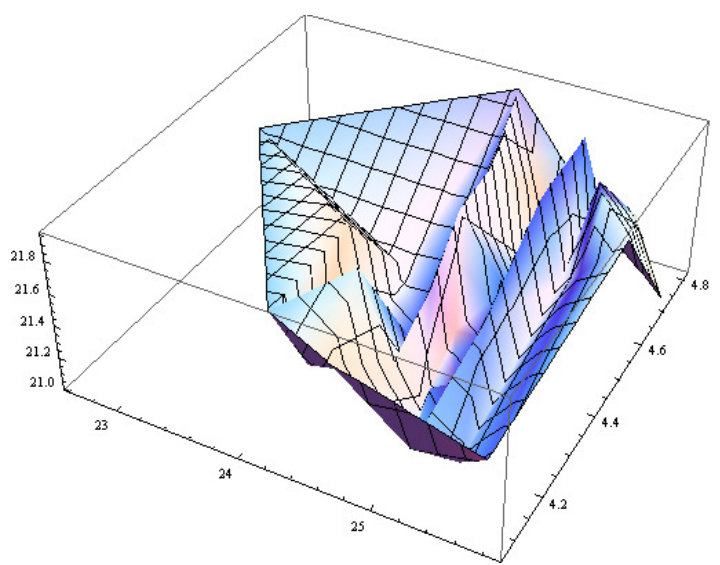

$\mathrm{x}$-axis: Expected return of cost-saving $(22.5 \%-26 \%)$ y-axis: Actual return of cost-saving $(21.0 \%-22.0 \%)$ Z-axis: Risk-free rate $(4.0 \%-4.8 \%)$

Figure 2: 3D visualisation for ECS Cost-saving

The 3D visualisation models are presented in Figure 2, which is the default 3D model that indicates a high return of cost-saving between $21 \%$ and $22 \%$ on the y-axis, which is significant reduction in operational costs. It also shows the expected cost-saving between 22 and $26 \%$ on $\mathrm{x}$-axis. The $\mathrm{z}$-axis presents risk-free rate $(4.0-5.0 \%)$, which means minimum expenses to keep operation running (including staffing costs). This percentage range can guarantee costsavings. With Cloud Computing, statistics can analyse the cost-saving from consumption and resources required. But the 3D calculation takes hidden areas such as staffing costs into consideration; fewer people are required to do the 
same amount of work. Similarly, Buyya et al. (2010) and Pajorova and Hluchy (2010) use 3D Visualisation to present Cloud Computing analysis and challenges.

\subsubsection{Quality Assurance of data and preparing to move to next service}

STATA is a statistical software and is rich with testing algorithms and data diagnosis, including verifying what has been computed to ensure a greater level of Quality Assurance (QA) (Dietmann et al., 2009). Chang et al. (2011 b; $2011 \mathrm{~d}$ ) demonstrate the QA process which aims to check data presented by 3D Visualisation is accurate and also assert Skewness/Kurtosis tests for Normality is suitable to test quality of 3D data. They explain the smaller the difference between chi-square distribution and likely probability (known as Prob>chi2), the less volatile and less predictable (or more stable) the data analysis is likely to be. Table 3 shows the result where y- and z-axis have very minimum volatility. The $\mathrm{x}$-axis refers to the actual cost-saving in percentage and $3 \mathrm{D}$ Visualisation is based on the analysis of collected data and statistical test presented in Section 4.1.1 and 4.1.2. The higher value in Prob $>$ chi2 may imply this possibility

- For some months, the cost-saving was more towards $22.5 \%$ and for some months, it was more towards $26 \%$, making the overall analysis more volatile.

This is a reasonable cause because in some academic terms, there is a higher consumption of energy and more operational costs involved. In vacation, it is quieter and there is a less tendency of using more energy and resources.

Table 3: Skewness/Kurtosis tests for Normality

\begin{tabular}{|c|c|c|c|c|c|}
\hline \multicolumn{6}{|c|}{ Skewness/Kurtosis tests for Normality } \\
\hline Variable I & Obs & $\operatorname{Pr}($ Skewness $)$ & $\begin{array}{c}------ \text { joint } \\
\operatorname{Pr}(\text { Kurtosis }\end{array}$ & ) adj chi2(2) & Prob $>$ chi 2 \\
\hline $\mathrm{X}$-axis I & 82 & 0.7916 & 0.3201 & 1.11 & 0.3740 \\
\hline $\mathrm{y}$-axis 1 & 82 & 0.7649 & 0.0094 & 6.30 & 0.0428 \\
\hline $\mathrm{z}$-axis I & 82 & 0.5257 & 0.0000 & 16.09 & 0.0003 \\
\hline
\end{tabular}

At the end of each step and service, results are also saved as text files which are readable by software such as SAS, Mathematica and MATLAB. They are passed to the next stage when the software program calls for text files as the input. This step is to ensure information from the previous service can be used for the next service.

\subsection{Risk Analysis as a Services (RAaaS)}

Simulations in Risk Analysis become more popular in organisations investing in new technologies and new areas. Risk Analysis as a Service (RAaaS) is a specialised area to present. Chang et al. (2011 a) describe how Financial Software as a Service (FSaaS), which is close to RAaaS, can work in the context of Clouds. This includes Monte Carlo Methods (MCM) and Black Scholes Models (BSM) are used to calculate pricing and risk, and present some selected results for visualisation particularly risk analysis. This ensures there is no hidden or missing data for risk analysis, and visualisation allows stake holders to understand the impacts of risk more easily. FSaaS can be used as a stand alone solution. Similarly, RAaaS can be used in the BIaS and to allow results from RMaaS to be used and presented as an integrated solution. RAaaS development is made up of the following sequence (see Table 4).

- Variance-Gamma Process (VGP) in MCM, focusing on error corrections.

- Least Square Method (LSM) in MCM, focusing on fast and reliable calculations with an excellent performance.

Table 4: RAaaS development following this sequence

\begin{tabular}{|c|c|c|c|}
\hline Sequence & Process & What is aimed for & Outcomes \\
\hline 1. & VGP in MCM & Detect and correct errors & $\begin{array}{l}\text { If errors are still found, run analysis again. The } \\
\text { improved analysis can be passed onto next sequence. }\end{array}$ \\
\hline 2. & LSM in MCM & $\begin{array}{l}\text { Provide fast and reliable } \\
\text { calculations with an } \\
\text { excellent performance. } \\
\text { Obtain benchmark. }\end{array}$ & $\begin{array}{l}\text { Most of calculations and benchmark can be obtained } \\
\text { here. If errors are found, go back and check. The } \\
\text { improved analysis can be passed onto next sequence. }\end{array}$ \\
\hline
\end{tabular}


Chang et al. (2011 a) describe financial models they use for risk and pricing analysis, in which they have adopted Monte Carlo Methods (MCM) for advanced risk calculations and Black Scholes Model (BSM) for 3D risk modelling. In this case, the ECS cost-saving is used for risk modelling, where the Least Square Methods (LSM) can be used to compute up to 100,000 simulations in one go to ensure a high level of accuracy.

\subsubsection{First step in RAaaS: Variance-Gamma Process}

Ribeiro and Webber (2002) demonstrate improved calculation techniques based on Monte Carlo Methods (MCM) on top of the Variance-Gamma Process (VGP), which has been a subject of a number of studies (Carr et al., 2002; Ribeiro and Webber, 2004). Brigo et al. (2007) demonstrate their risk modelling process and explains how VGP reduces inconsistency with coding algorithm presented. Error corrections in financial modelling are important and when errors are identified, rectifications need to be found and applied automatically wherever possible (Zimmermann, Neuneier and Grothmann, 2006). The reason is that slight discrepancies in financial analysis can lead to adverse impacts such as financial loss. Variance-Gamma Processes (VGP) is a technique of MCM used for error corrections. VGP offers two benefits:

It simulates the pricing and risk analysis using raw data which includes good and out of range data.

It removes out of range of data, recomputes simulations and presents the improved simulations.

Results from RMaaS are passed onto RAaaS as the key variables for VGP, the first step of RAaaS. Referring to Figure 3, the top half shows original variables following gamma distribution. The lower half shows the stratifying variables from gamma distribution. The stratifying model eliminates infrequent variables and also concentrates on more frequently-seen results, giving more accurate results than the original modelling by MCM. The code can facilitate similar tests for different variances for volatility, maturity and risk free rate. The core code algorithm is explained in the Appendix.
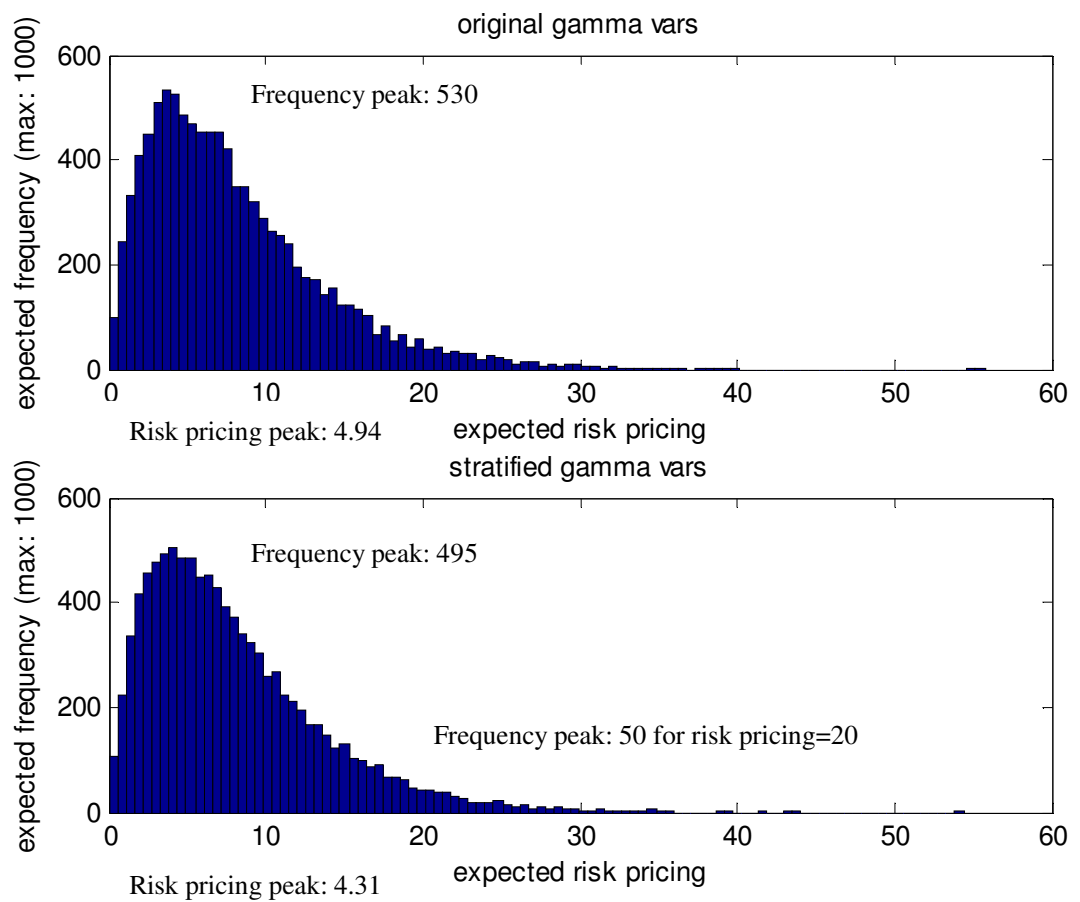

Figure 3: Error correction by VGP: Risk pricing and frequency of occurrence for University of Southampton

Figure 3 shows the improved data for risk analysis with VGP gamma distribution where the expected frequency of occurrence is 495 instead of 530 before correction takes place. Expected risk pricing means the expected measurement of risk which has implications for costs and sometimes it can be expressed in terms of percentage (Hull, 2009). In other words, it can be interpreted that an expected risk pricing of 4.31 means the risk will cost $4.31 \%$ of your total operation. Here is an example. A project suffers from accidents such data loss and some data can be retrieved easily. Some loss of data needs to hire additional employees and resources to obtain the data from other sources and organisations. The highest frequency of occurrence corresponds to $4.31 \%$ of expected risk pricing, which means it cost $4.31 \%$ of total expenditure when such an incident happen. Another example is the loss of data centre due to fire and it estimates to cost $20 \%$ of the total expense of the year. Referring to Figure 3 , the expected 
frequency of occurrence is 500 out of 1000. Although it has a lower frequency of occurrence, it still poses risk. The purpose is for us to identify the likelihood for higher risks which is crucial for risk management.

\subsubsection{Second step in RAaaS: Least Square Method}

Risk analysis is useful for organisation to understand the extent of business and operational risks, which can be varied from time to time. To perform risk modelling, American and European options are used, as both models are popular choices within MCM for financial risk analysis. American option is an option that can be exercised anytime during its life. The majority of exchange-traded options are American. A European option may be exercised only at the expiry date of the option, which means at a single pre-defined point in time (Hull, 2009). Adopting both options are suitable because American option can calculate the average performance, and European option can calculate the best pricing or risk at the time that research work takes place. Risk and pricing modelling can use both options, where the University of Southampton has requested.

LSM is well-known for making accurate and high-performing simulations to compute reliable results. LSM is chosen because of the following advantages. Firstly, LSM provides a direct method for problem solving, and is extremely useful for linear regressions. LSM only needs a short starting time, and is therefore a good choice. Secondly, Terms Structure Models and Triangular Methods are not necessarily used in the Clouds. LSM can be used in the Clouds, because often jobs that require high computations in the Clouds, need extensive resources and computational powers to run. LSM is suitable if a large problem is divided into several sections where each section can be calculated swiftly and independently. This also allows improvements in efficiency (Longstaff and Schwartz, 2001; Moreno and Navas, 2001; Choudhury et al., 2008; Chang et al., 2011 a).

Chang et al (2011 a) explain how 100,000 simulations on Clouds can be achieved by adopting Least Square Method (LSM) in MATALAB. This makes simulations to be completed in 4 seconds if the time step (a variable in LSM and $\mathrm{MCM}$ ) is equal to 10. MATLAB (primary language) is written at the backend and C\# is written for frontend to facilitate a large number of simulations. Core MATLAB code algorithm has been explained in Chang et al (2011 a). The following is the result of running LSM to calculate the expected risk price.

$$
\begin{aligned}
& \text { MCAmericanPrice }=4.9421 \\
& \text { MCEuropeanPrice }=4.3168
\end{aligned}
$$

Both American and European options can be converted to percentage, which can represent the percentage of getting this risk analysis (Hull, 2009; Lee et al., 2010). This means the risks of having operational risks (electricity, staff and unexpected costs) will be $4.9421 \%$ and $4.3168 \%$ respectively. Referring to 4.2.1, European option is closer to the corrected result of risk analysis and this implies our risk analysis follows European option more than American option. Figure 4 shows the time taken to execute accurate risk calculations, which are between 10,000 and 100,000 simulations based on MCM.

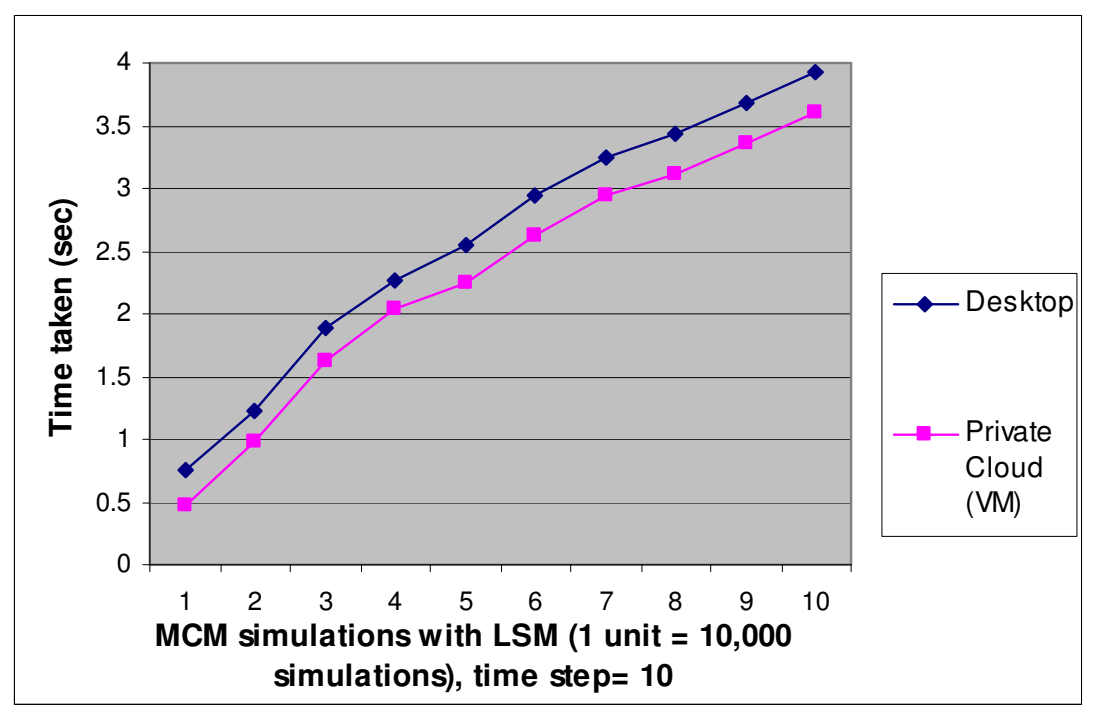

Figure 4: Time taken in MCM simulations 
The next challenge is calculate the range of lower, upper and medium limit. Although Figure 4 shows the range of upper and lower limit, it indicates a wide range of 1.5 and 6.5. This has to be much tightened up to calculate the likely range of risk pricing with the most frequency of occurrence. It means we have to calculate a closer range. The result shows the expected European option (for risk price) is 4.312682 with its upper limit as 4.364596 and lower limit as 4.260768. As explained in Section 4.2.1, risk price can be presented in percentage to show the percentage of loss if such risks happen. It also means the expected risk price is $4.312682 \%$ with its upper limit as $4.364596 \%$ and lower limit as $4.260768 \%$ if risks are presented in percentage.

\section{[LowerLimit MCPrice UpperLimit]}

Call Prices: [4.260768 4.312682 4.364596]

Table 5 shows the core algorithm for calculation and blue text indicate key variables computed by RMaaS and the first step of RAaaS. There are also occasions that these key variables are provided by the collaborator. If that is the case, those key variables need to be checked and computed by the first step of RAaaS to ensure the input data is accurate.

Table 5: Core algorithm showing the risk pricing calculation

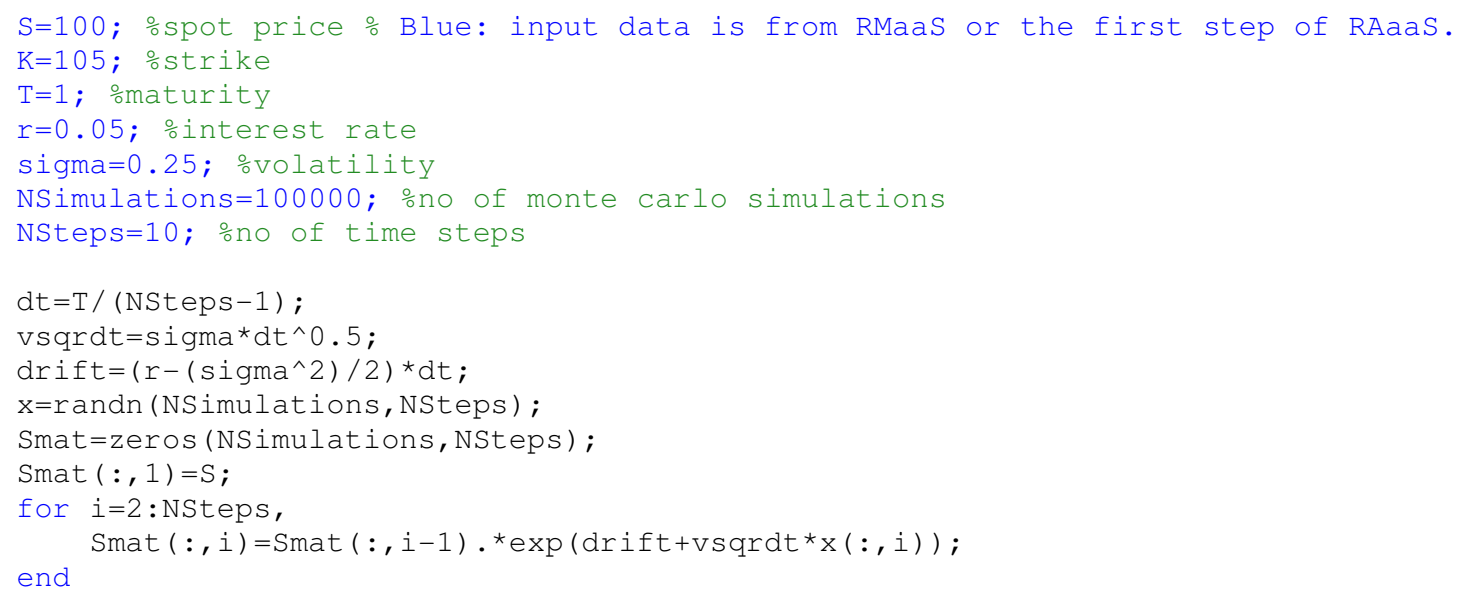

Call price means the expected value and in financial engineering, it can be presented as risk (Hull, 2009; Lee et al., 2010). Table 6 show the core algorithm for calculating call price.

Table 6: The call price calculation for risk

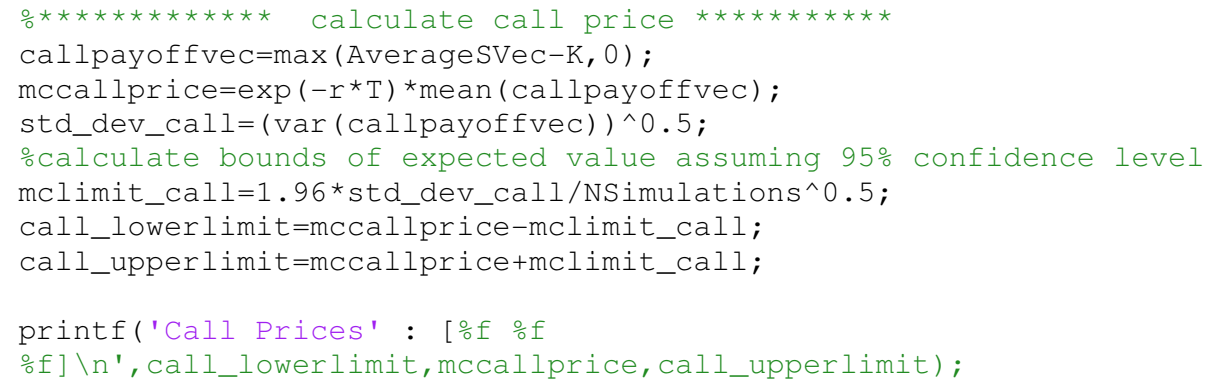

If risks are not dealt with in time, it is likely for it to grow when time goes by. It is important to find out the extent that risks are likely to grow to the point that is under control. If risks exceed the corporate management and organisations to ability to manage, it will cause serious consequences or a large sum of funding to sustain the situation. Although put prices mean the ideal prices for sale, it can be related to the maximum risk price that the organisations can get hold of (Hull, 2009). Hence, we need to find the maximum risk price that the organisation can manage without additional help or funding. 
Table 7 shows the core algorithm. The result also shows the expected maximum risk price is 7.640954 with its upper limit of 7.696455 and lower limit of 7.585452. Similarly, these results can be presented in percentage.

Put Prices: [7.585452 7.640954 7.696455]

Table 7: The put price calculation for risk

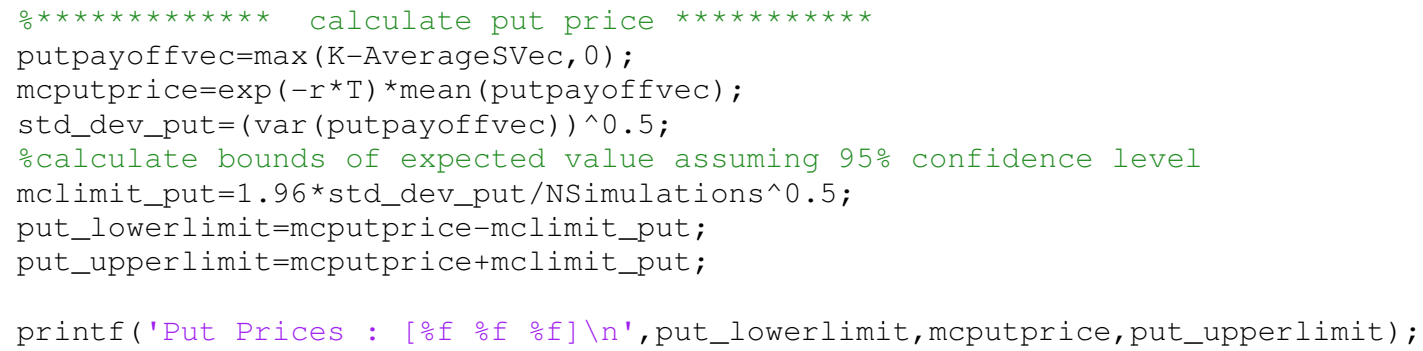

The integration between RMaaS and RAaaS demonstrates the benefits for University of Southampton. It computes the cost-saving analysis and presents results in statistics and 3D with a QA process. Secondly, results from RMaaS and additional information from collaborator can be used for RAaS, which uses VGP to reduce errors and identifies the likely range for risk pricing. RAaaS then uses LSM to calculate the best risk pricing and much narrows down the range and it also calculates the maximum risk pricing that organisation can handle without getting additional assistance.

\subsection{Integration of RMaaS and RAaaS for University of Southampton}

This case study is about managing Cloud and utility computing to minimise costs and risks, and demonstrates how to integrate two services, RMaaS and RAaaS, so they can be viewed as a single service. RMaaS service includes three steps. The first step involves statistical service to compute several key data and variables, which are passed onto the second step, 3D Visualisation service, to present its cost-return analysis visually with actual return between 21 and $22 \%$ against expected return between 22.5 and 26\%. The result is then passed to the third step, QA service, which checks data reliability and suggests implications from data analysis. Selected output from RMaaS together with management's data is passed on the first step of RAaaS, which offers VGP service to reduce errors and calculate the risk price. The outcome is passed to the second step of RAaaS, which offers LSM service to provide a precision technique to calculate the exact risk pricing and its maximum risk pricing. LSM also can compute 100,000 simulations per service to ensure an accurate and reliable result. This data is useful for University management board.

\section{BlaS Case Study for Vodafone/Apple}

The telcommunications giant Vodafone operates cloud computing business as a Service Provider, One-Stop Resources/Services and Entertainment and Social Networking, which correspond to our first, fifth and eighth business models by the Cloud Cube Model (Chang et al., 2010 b). Entertainment and Social Networking is an area for major profits in 2010, where Vodafone aims to get $£ 11.8$ billions of profits since they are a major iPhone bundle seller with a surge in iPhone demands (City A.M, 2010). Their strategy is to focus on lucrative iPad sale that is predicted to sell over 1 million units including wireless broadband and related services. Vodafone is thus a cloud service provider, and they fit well into cloud computing by providing mobile cloud and entertainment services via iPhone. Despite the fact that Apple can be considered as a mobile cloud provider (Chang, et al., 2010 a; 2010 b; 2010 c), it still needs infrastructure providers such as Vodafone, Orange, $\mathrm{O} 2$ and so on to deliver its services to millions of clients. Additional applications and APIs such as teleconferencing, remote access, GPS, VoIP and so on require telecom services to be available. Those who buy iPhones are mainly interested in SaaS services that both Apple and Vodafone offer (City A.M, 2010). Thus, we assert both Vodafone and Apple are considered as adoption of SaaS cloud business sustainability, even though they still require hardware and infrastructure to support.

\subsection{ROI Measurement as a services (RMaaS)}

Although surveys and interviews provide direct feedback and allow data to be obtained without concerns of leaking confidential data, both research methods can be a prolonged process since it requires building trust and collaboration with helpful participants. We are still in the process of getting more Vodafone managers and major customers to 
provide us with feedback. The one-year research data for this case study is purchased via reputable financial sources including the Wall Street Journal and the City A.M where they have included case studies and business data for Vodafone and numerous global organisations.

\section{Table 8: Auto regression summary for Vodafone with iPhone strategies}

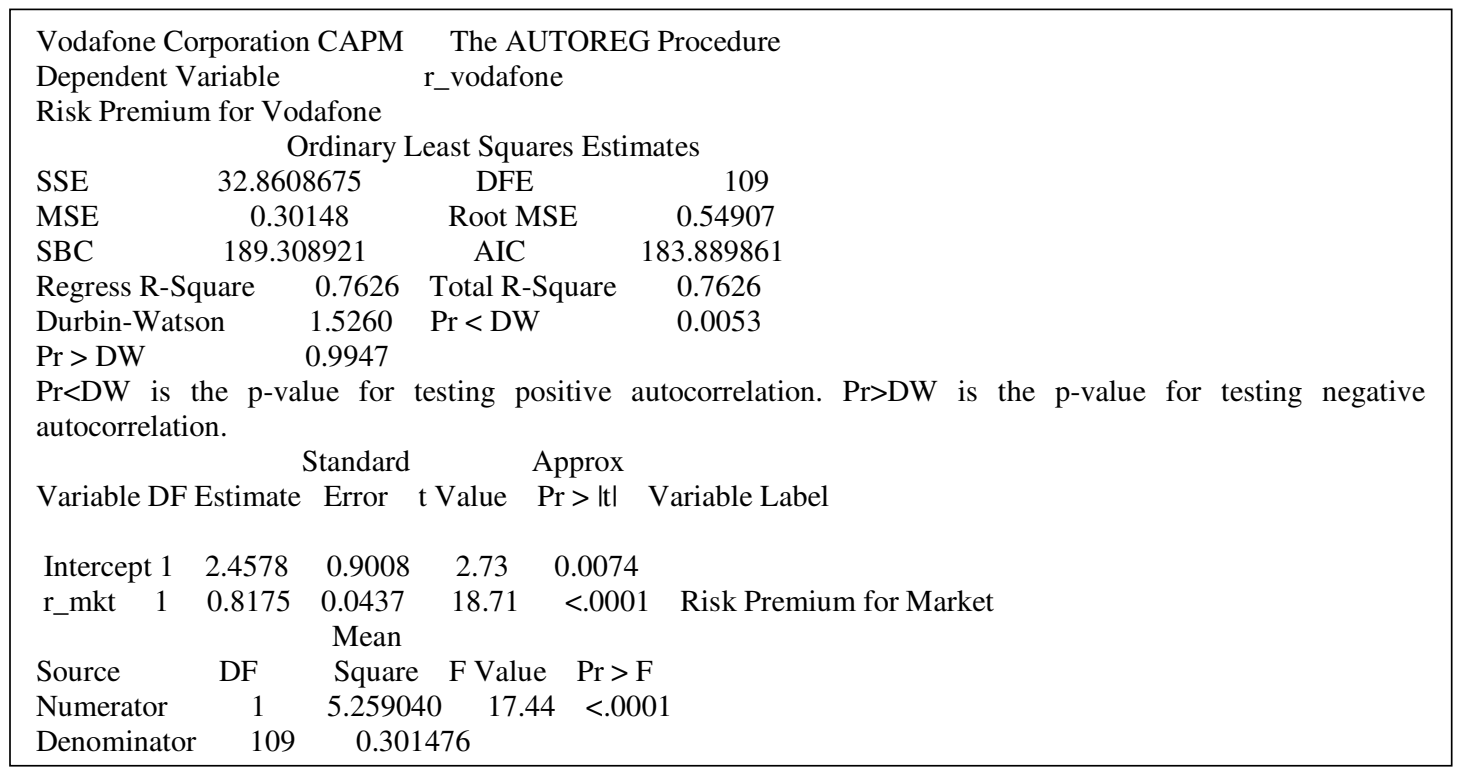

Referring to Figure 5, the green line is the predicted value, and the red line as the upper limit and the blue dotted line as the lower limit. It presents a high market returns for Vodafone with low risks involved, mainly because iPhone was proven an extremely successful sale and profit-maker in 2009 . The estimate is between $16.5 \%$ and $23.0 \%$ of profits, and is more likely (green line) between $17.0 \%$ and $22.0 \%$. This is from a reliable source that we need not worry about defining which group of data to be focused on. Durbin-Watson method is used for statistics tests.

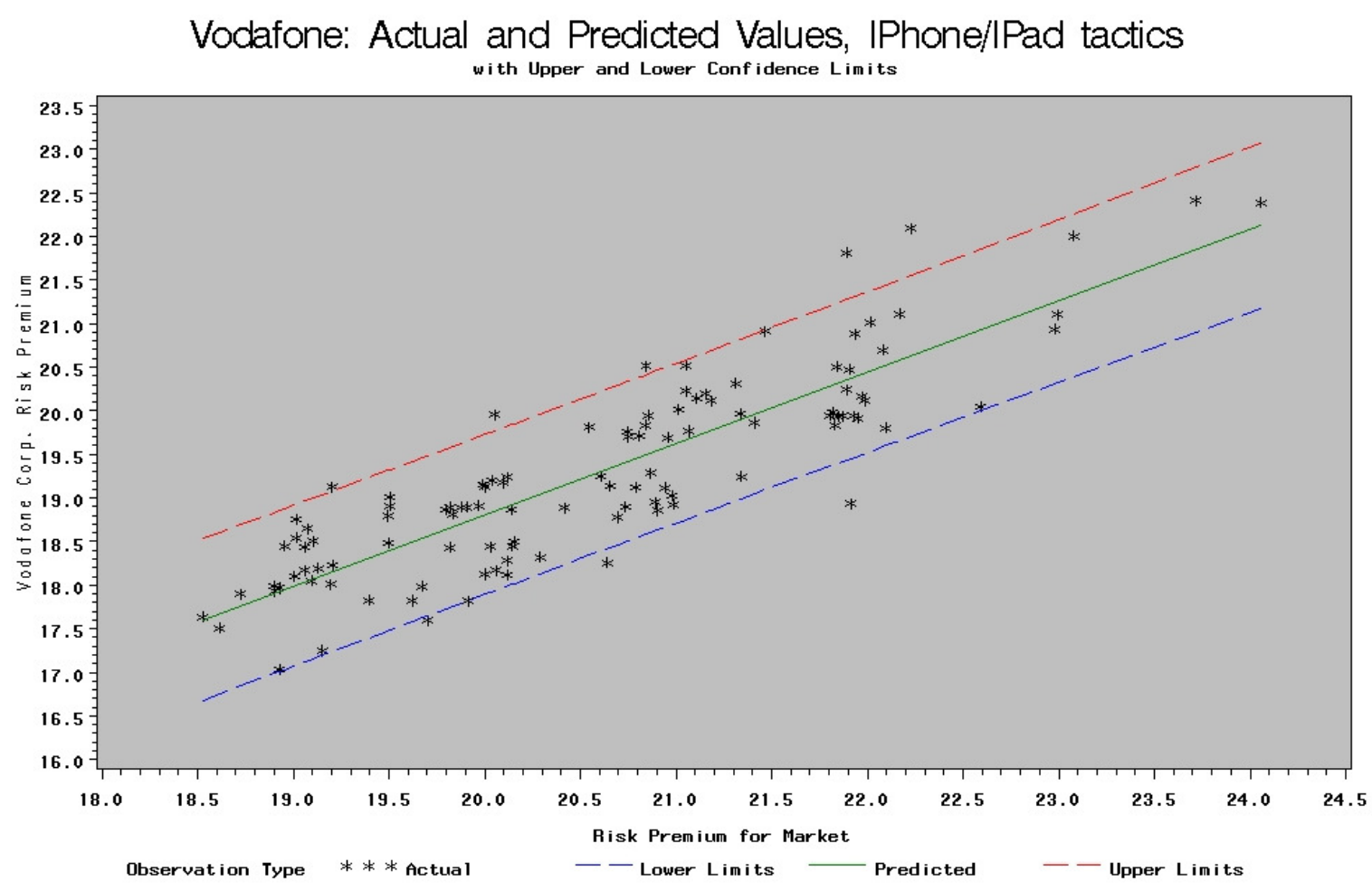

Figure 5: Vodafone actual and predicted Risk Premium 


\subsubsection{D Visualisation for Vodafone's iPhone strategy within RMaaS}

Data is computed in Mathematica and the 3D visualisation models are presented in Figure 6 and Figure 7 respectively, where Figure 6 is the default 3D model that indicates a high return of between $21 \%$ to $25 \%$ additional profits offered by iPhone bundle sell. Figure 7 provides a more detailed view related to its cloud business performance, which suggests it goes high and maintains a momentum upwards with few additional unexpected results as spikes. The $\mathrm{x}$-axis presents Vodafone's return (21-24\%), the y-axis presents risk premium of the market return $(22-26 \%)$, and the $\mathrm{z}$-axis presents risk-free rate in market $(2.0-4.0 \%)$.

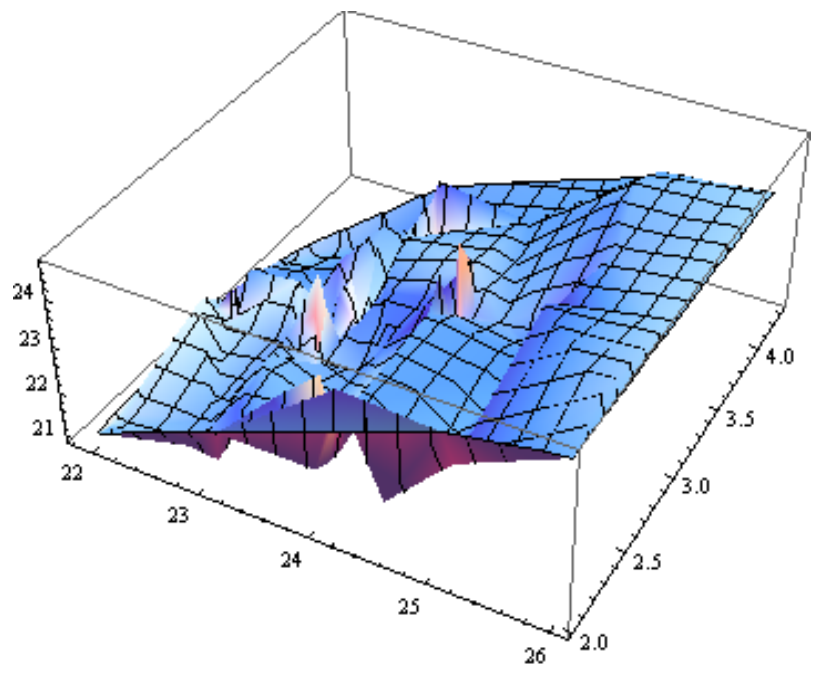

- $x$-axis: Vodafone's return (21-24\%)

- $y$-axis presents risk premium of the market return $(22-26 \%)$

- $\mathrm{z}$-axis presents risk-free rate in market $(2.0-4.0 \%)$

Figure 6: 3D visualisation for Vodafone

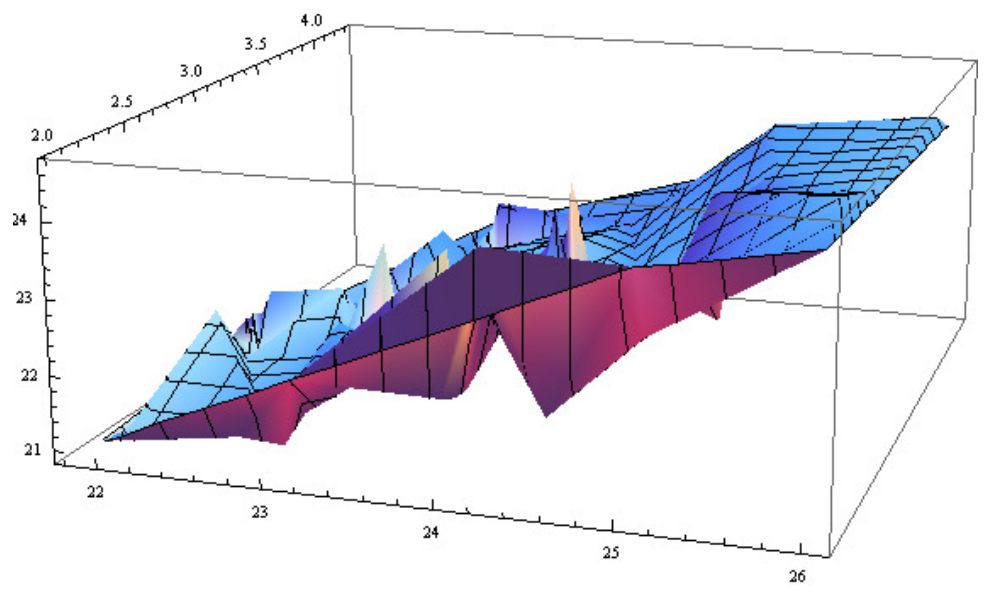

Figure 7: 3D visualisation for Vodafone, detailed view.

\subsubsection{Quality Assurance of data and preparing to move to next service}

Similar to Section 4.1.3, the objective is to ensure a QA process for data presented in 3D Visualisation. Table 9 shows Skewness/Kurtosis tests for Normality where the smaller the value Prob>chi2 is, the more stable (or less volatile) the data analysis is. Both $\mathrm{x}$-axis and $\mathrm{z}$-axis are very stable due to very minimal difference. The $\mathrm{y}$-axis has a higher value for Prob>chi2. This may mean the market return is less predictable comparing to previous sales. It may include the following reasons:

- More competitions with other network service providers selling iPhones and iPads;

- More competitions with other phones such as Android-based phones;

- Market becomes less predictable due to current economic climate. 
Table 9: Skewness/Kurtosis tests for Normality for Vodafone with iPhone strategies

\begin{tabular}{|c|c|c|c|c|c|}
\hline \multicolumn{6}{|c|}{ Skewness/Kurtosis tests for Normality } \\
\hline Variable I & Obs & $\operatorname{Pr}($ Skewness) & $\operatorname{Pr}$ (Kurtosis) & adj chi2(2) & 2) Prob $>$ chi 2 \\
\hline $\mathrm{x}$-axis I & 111 & 0.0754 & 0.1075 & 5.58 & 0.0616 \\
\hline$y$-axis I & 111 & 0.9383 & 0.1735 & 1.90 & 0.3868 \\
\hline $\mathrm{z}$-axis I & 111 & 0.0200 & 0.0205 & 9.39 & 0.0091 \\
\hline
\end{tabular}

\subsection{Risk Analysis as a Service (RAaaS) for Vodafone/Apple}

A foreseeable risk is that there are more mobile network providers offering iPhone 4 and 4 S, Vodafone may lose competitions such as Network 3 or Orange/T-Mobile joint venture, thus they need evolve their cloud business models. This may include exploring new territories with selling Android-based mobile phones. Similarly, they need to change other cloud business strategies while competitions for smart phone markets and other mobile service providers soar in recent years. In order to calculate risk price, results from RMaaS need to pass onto RAaaS. This involves two steps: VGP and LSM to calculate the risk pricing.

\subsubsection{VGP risk pricing calculation}

Figure 8 shows risk pricing and frequency of occurrence for Vodafone/Apple strategy aiming error correction offered by VGP. The upper half figure show the original data with gamma distribution which has dual peaks, 385, for its frequency of occurrence and dual peaks of 20 and 23 for risk pricing. The lower half figure show the stratified data with gamma distribution and the correction is done by VGP. The rectified peak is 380 for its frequency of occurrence and the rectified peak is 21 for risk pricing.
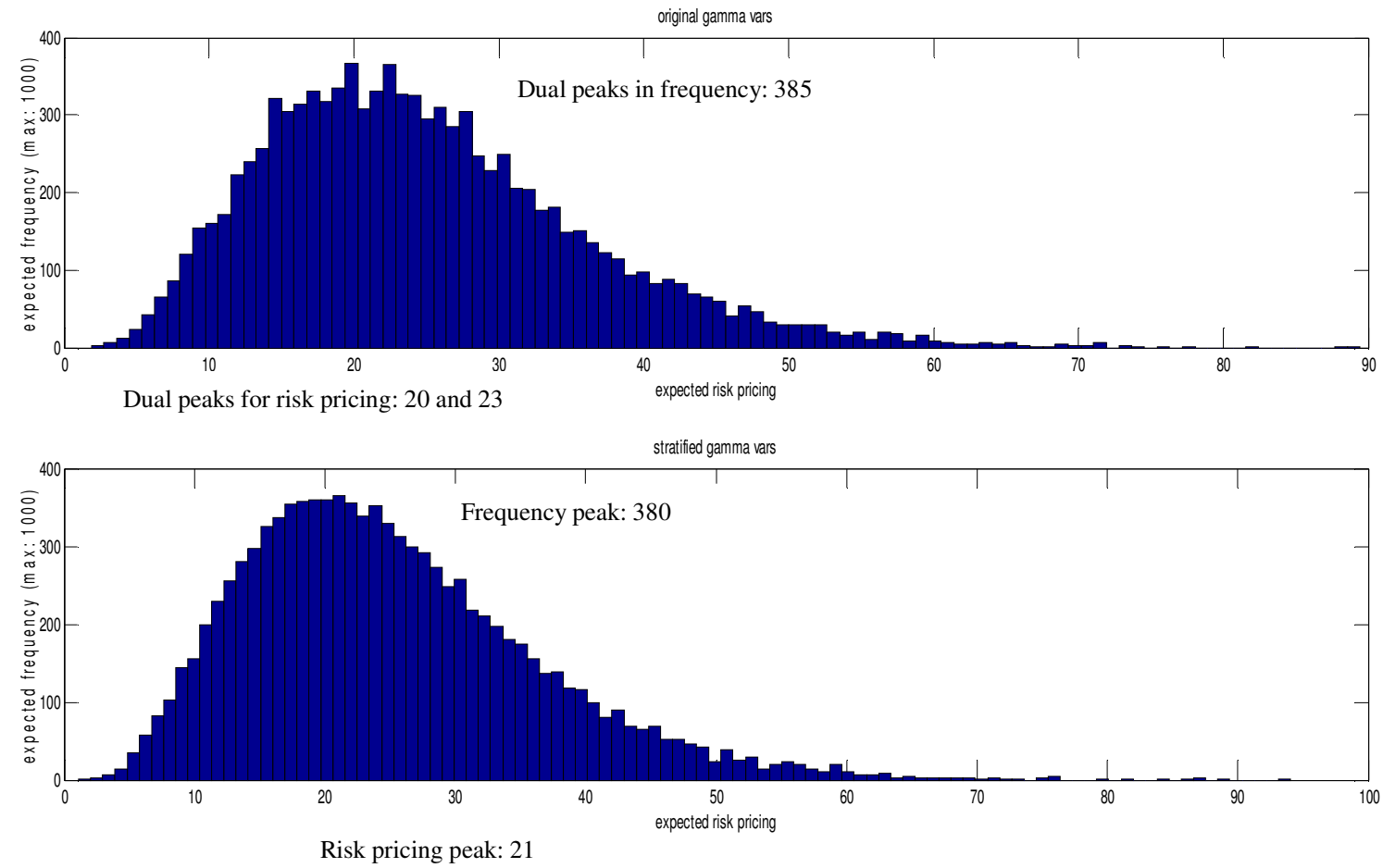

Figure 8: Error correction by VGP: Risk pricing and frequency of occurrence for Vodafone/Apple strategy. 


\subsubsection{LSM risk pricing calculation}

Results from Section 5.2.1 is passed to the second step of RAaaS used by LSM, which calculates a more accurate risk pricing. Chang et al (2011 a) explain the code algorithm for their program and the calculation for both American and European options are presented as:

MCAmericanPrice $=23.8412$

MCEuropeanPrice $=21.1682$

Comparing results with Figure 8, European option is closer to the corrected result of risk analysis and this implies our risk analysis follows European option more than American option. Similar to Section 4.2.2, risk pricing can be presented as percentage which means if sales do not meet Vodafone/Apple's target expectation, the percentage of underperformance below their target expectation. In other words, the percentage of underperforming is $21.1682 \%$ if the sale goes down due to volatile economic climate or tough contests with market competitors and such a probability for frequency occurrence is 0.38 (380 out of 1000). Following the code algorithm in Section 4.2.2, the next task is to calculate the most likely range of the risk pricing.

$$
\begin{aligned}
& \text { [LowerLimit MCPrice UpperLimit] } \\
& \text { Call Prices: [20.490137 21.189824 22.289510] }
\end{aligned}
$$

The result show the most likely risk pricing is 21.189824 with its upper limit as 22.289510 and lower limit as 20.490137. This means if Vodafone loses out its competitors or has lower sales due to economic climate, it will impact $21.189824 \%$ to its businesses and overall revenues and upper limit of $22.289510 \%$ and lower limit as $20.490137 \%$.

There is a need to find out the maximum risk pricing that Vodafone can manage without getting additional resources and funding and this result is important for stake holders. Core code algorithm is explained in Section 4.2.2. Computational result show the most likely risk pricing is 23.940547 with its upper limit as 25.086512 and lower limit as 22.794581. Similarly, risk pricing can be presented in terms of percentage and result suggest that it will impact $23.940547 \%$ to its businesses and overall revenues and upper limit of $25.086512 \%$ and lower limit as $22.794581 \%$. Once risk goes beyond the upper limit, Vodafone needs to get additional assistance and funding.

\section{[LowerLimit MCPrice UpperLimit]}

Put Prices: [22.794581 23.940547 25.086512]

Interestingly enough, each iPhone and iPad sale in countries do not report to have sales problems since these products have been sought after by many users. Although competitions between different network service providers have been tense, others do not seem to pose a big threat (City A.M, 2011). More up-to-date data will then support our rationale in the near future.

\subsection{Integration of RMaaS and RAaaS for Vodafone/Apple}

This case study is about profits from iPhone and iPad sales and operations and using Cloud to optimise profits versus risk, and demonstrates integration of RMaaS and RAaaS, so they can be viewed as one service. The first step of RMaaS involves statistical service to compute several key data and variables, which are passed to the second step, $3 \mathrm{D}$ Visualisation service, to present its cost-return analysis visually with actual return between 21 and $24 \%$ against expected market return between 22 and $26 \%$. The result is then passed to the third step, QA service, which checks data reliability and suggests implications from data analysis. Selected output from RMaaS is passed onto the first step of RAaaS, which offers VGP service to reduce error and calculate the risk price. The outcome is passed to the second step of RAaaS, which offers LSM service to provide a precision technique to calculate the exact risk pricing and maximum risk pricing. Those key data is useful for current and potential investors.

\section{Discussions}

BIaS provides linkage between different types of services and this offers efficiency improvement and time reduction in business processes. Each sequence of activities in BIaS is distinctive but different services in BIaS can work together within the framework in which all services use data formats which are readable by others. Output from one process can be used by the next. In this way BIaS is able to integrate different services and business activities and ensure a streamline process in place. 
Benefits from BIaS adoption include improvements in efficiency, cost reductions, improved risk analysis and connecting business activities together. These are demonstrated in two case studies. In the first, the University of Southampton derived benefits of computing cost-saving and risk analysis of Cloud adoption and integration of different activities from different departments. In the second, Vodafone/Apple gained quantified understanding of the impacts on their revenues of risks arsing from tough market competitions

\subsection{How BIaS can be used by organisations}

Of the two case studies presented, the University of Southampton has gained the more positive impacts as a result of BIaS and Linkage. The cost-saving performance has an expected return of cost-saving between $22.5 \%$ and $26 \%$ and the actual return cost-saving is between 21.0 and $22.0 \%$. This is above the business analysts' initial forecasts of around $10 \%$, a basic forecast based on previous experience without adopting Cloud. With the QA process in place to ensure 3D analysis is of high quality, the added percentage of cost-saving is due to the use of virtualisation, Green IT policies and on-demand usage that can eliminate underutilised resources and ensure resources are only in use when there is a demand. RAaaS detects and corrects inconsistencies and narrows down the risk price using VGP. LSM is then used to calculate more accurate risk pricing with upper and lower limits identifiedusing high-performing simulations. Our case studies also demonstrate how different layers of services such as PaaS and SaaS can be used together in an integrated way. The way BIaS can be used by organisations and its key benefits and features are summed up in Table 10.

Table 10: How BIaS can be used

\begin{tabular}{|c|c|c|c|c|}
\hline $\begin{array}{l}\text { Types of } \\
\text { BIaS }\end{array}$ & Case studies & $\begin{array}{l}\text { Key benefits to } \\
\text { adopting } \\
\text { organisations }\end{array}$ & $\begin{array}{l}\text { What type of business } \\
\text { orientation for service } \\
\text { providers? }\end{array}$ & $\begin{array}{l}\text { Additional features } \\
\text { and remarks }\end{array}$ \\
\hline $\begin{array}{l}\text { Integration of } \\
\text { RMaaS and } \\
\text { RAaaS }\end{array}$ & $\begin{array}{l}\text { University of } \\
\text { Southampton Cost- } \\
\text { saving and risk } \\
\text { analysis. } \\
\\
\text { Vodafone/Apple }\end{array}$ & $\begin{array}{l}\text { It can integrate different } \\
\text { business activities. It } \\
\text { can compute cost- } \\
\text { saving, risk and any } \\
\text { risk related analysis. It } \\
\text { helps stake holders to } \\
\text { make good decisions. }\end{array}$ & $\begin{array}{l}\text { Consultancy. } \\
\text { providers using CCBF, } \\
\text { can offer valuable } \\
\text { consultancy to design } \\
\text { and deploy Cloud } \\
\text { services based on } \\
\text { clients' needs. }\end{array}$ & $\begin{array}{l}\text { This integration has a } \\
\text { high research and } \\
\text { commercial values. The } \\
\text { benefits include } \\
\text { improvement in } \\
\text { efficiency, cost } \\
\text { reduction, risk analysis } \\
\text { and connect business } \\
\text { activities altogether }\end{array}$ \\
\hline $\begin{array}{l}\text { Automated } \\
\text { and secure } \\
\text { Risk Software } \\
\text { as a Service }\end{array}$ & $\begin{array}{l}\text { University of } \\
\text { Southampton }\end{array}$ & $\begin{array}{l}\text { This service introduces } \\
\text { three step process, } \\
\text { which calculate risks in } \\
\text { depth and also present } \\
\text { them in 3D. } \\
\text { Automation will ensure } \\
\text { all three steps are done. }\end{array}$ & $\begin{array}{l}\text { It can be consultancy or } \\
\text { software contractor. } \\
\text { Consultancy is a better } \\
\text { model as SaaS } \\
\text { development needs to } \\
\text { fully understand } \\
\text { business process and } \\
\text { integration. }\end{array}$ & $\begin{array}{l}\text { Simulations for EU } \\
\text { crisis have been } \\
\text { calculated and } \\
\text { presented. This work is } \\
\text { not for this paper. }\end{array}$ \\
\hline
\end{tabular}

\section{Conclusion}

This paper presents Business Integration as a Service (BIaS). Its objective is to connect different services together into an integrated environment, with the output of one service being used as input to the next bringing business activities together. The combined use of Risk Analysis and Quality Assurance also allows risk control and data quality to be reviewed and monitored which helps management to make good, informed, decisions.

BIaS is part of a framework, Cloud Computing Business Framework (CCBF), to help organisations to achieve good Cloud design, deployment and services. CCBF has been extensively used in several organisations such as GSTT, KCL, Universities of Greenwich, Southampton, Oxford, VMware, Vodafone/Apple, Salesforce, IBM. Contributions from BIaS and CCBF will and have positively impacted some of e-Research, Cloud, Grid, Health, Finance and Education Communities.

Two case studies in this paper show BIaS in action integrating RMaaS with RAaaS at the University of Southampton and at Vodafone/Apple. At University of Southampton this has reduced the level of manual data extraction and 
enabled management to quantify the extent of its cost-saving compared with associated risks so that stake-holders could make the right decisions. The case study at Vodafone/Apple describes statistical analysis and 3D Visualisation of expected revenue with QA process in place in tough market conditions. Risk price calculations presented this way have been useful for stake-holders.

The key advantage of adopting BIaS is to allow different services to be performed, computed and managed in one platform. This saves time and resources compared with performing activities at different times and locations. It improves efficiency, and consolidates streamlining of processes and communications between different departments of large organisations.

\section{Reference}

Ahronovitz, et al. [about 30 authors], "Cloud Computing Use Cases White Paper", Version 4.0, National Institute of Standards and Technology, July 2010.

Armbrust, M., Fox, A., Griffith, R., Jseph, A. D., Katz, R. H., Kownwinski, A., Lee, G., Patterson, D., Rabkin, A., Stoica, I., Zaharia, M., "Above the Clouds: A Berkeley View of Cloud computing". Technical Report, No. UCB/EECS-2009-28, UC Berkeley, Feb 2009.

Bhaskaran, K.; Jen-Yao Chung; Das, R.; Heath, T.; Kumaran, S.; Nandi, P., "An e-business integration and collaboration platform for B2B e-commerce", Third International Workshop on Advanced Issues of E-Commerce and Web-Based Information Systems, WECWIS 2001, San Juan, CA , USA , 21 - 22 Jun 2001.

Boss, G., Malladi, P., Quan, D., Legregni. L., and Hall, H., “Cloud Computing”, IBM white paper, Version 1.0, October 2007.

Brandic, I., Music, D., Leitner, P. and Dustdar, S., "VieSLAF Framework: Enabling Adaptive and Versatile SLA-Management.", the 6th International Workshop on Grid Economics and Business Models 2009 (Gecon09), 25- 28 August 2009, Delft, The Netherlands.

Brigo, D., Dalessandro, A., Neugebauer, M. and Triki, F., "A Stochastic Processes Toolkit for Risk Management", Working Paper, King's College London, November 2007.

Briscoe, G. and Marinos, A., "Digital ecosystems in the clouds: towards community cloud computing”. In: IEEE 2009 the 3rd IEEE International Conference on Digital Ecosystems and Technologies (DEST 2009), New York, USA, pp. 103-108.

Buyya, R., Yeo, C. S., Venugopal, S., Broberg, J. and Brandic, I., "Cloud computing and emerging IT platforms: Vision, hype, and reality for delivering computing as the 5th utility", Journal of Future Generation Computer Systems, Volume 25, Issue 6, June 2009, Pages 559-616.

Buyya, R., Ranjan, R. and Calheiros, R. N., "InterCloud: Utility-Oriented Federation of Cloud Computing Environments for Scaling of Application Services", Algorithm and Architectures for Parallel Processing, Lecture Notes in Computer Science, 2010, Volume 6081/2010, 13-31.

Carr, P., Geman, H., Madan, D., and Yor, M., "The fine structure of asset returns: An empirical investigation", Journal of Business, 75 (2), 305-332, 2002.

Chang, V., Bacigalupo, D., Wills, G., De Roure, D., “A Categorisation of Cloud Computing Business Models”, CCGrid 2010 IEEE conference, Melbourne, Australia, May 2010 (2010 a).

Chang, V., Wills, G. and De Roure, D., "A Review of Cloud Business Models and Sustainability”, IEEE Cloud 2010, the third International Conference on Cloud Computing, 5-10 July 2010, Miami, Florida, USA (2010 b).

Chang, V., Wills, G. and De Roure, D. (2010) Cloud Business Models and Sustainability: Impacts for businesses and e-Research. In: UK e-Science All Hands Meeting 2010, Software Sustainability Workshop, 13-16th September, 2010, Cardiff (2010 c).

Chang, V., Li, C.S, De Roure, D., Wills, G., Walters, R. and Chee, C., "The Financial Clouds Review", International Journal of Cloud Applications and Computing, 1 (2). pp. 41-63. ISSN 2156-1834, (2011 a).

Chang, V., De Roure, D., Wills, G., Walters, R. and Barry, T., "Organisational Sustainability Modelling for Return on Investment: Case Studies presented by a National Health Service (NHS) Trust UK”. Journal of Computing and Information Technology, 19 (3). ISSN Print ISSN 1330-1136 (2011 b)

Chang, V., De Roure, D., Wills, G. and Walters, R. (2011) Case Studies and Organisational Sustainability Modelling presented by Cloud Computing Business Framework. International Journal of Web Services Research, 8 (3). pp. 26-53. ISSN 1545-7362 (2011 c)

Chang, V., Wills, G. and Walters, R., "Towards Business Integration as a Service 2.0 (BIaS 2.0)". In: IEEE International Conference on e-Business Engineering, The 3rd International Workshop on Cloud Services - Platform Accelerating e-Business , 19-21 October, 2011, Beijing, China (2011 d). 
Chang, V., Wills, G., Walters, R. and Currie, W., "Towards a structured Cloud ROI: The University of Southampton cost-saving and user satisfaction case studies", Sustainable Green Computing: Practices, Methodologies and Technologies (In Press) (2011 e).

Chou, T., "Seven Clear Business Models”, Active Book Press, 2009.

Choudhury, A.R., King, A., Kumar, S. and Sabharwal, Y., “Optimisations in Financial Engineering: the Least-Squares Monte Carlo method of Longstaff and Schwarts”, IEEE International Parallel and Distributed Computing, IPDPS 2008.

Christudas, B. D., “Service Oriented Java Business Integration”, Book, published by Packt, ISBN: 978-1847194404, February 2008.

De Roure, D., Page, K.R., Fields, B., Crawford, T., Downie J. S., and Fujinaga, I., "An e-Research Approach to Web-Scale Music Analysis", in Philosophical Transactions of the Royal Society Series A, 2011.

Dietmann, A., Helbok, R., Lackner, .P, Fischer, M., Reindl, M., Lell, B., Issifou, S., Kremsner, P. and Schmutzhard, E., "Pathophysiology and severe malaria - from basic knowledge to new therapeutic approaches", Europena Journal of Tropical Medicine and International Health, Vol. 14, Issue 2, September 2009.

Frohlich M. T. and Westbrook R., "Demand chain management in manufacturing and services: web-based integration, drivers and performance, Journal of Operations Management, Volume 20, page 729-745, 2002.

Foster, I., Zhao, Y., Raicu, I., Lu, S. Y. (2008), "Cloud Computing and Grid Computing 360-Degree Compared", IEEE Grid Computing Environments (GCE08), 12-16 Nov 2008, Austin, Texas, USA.

Höing, A., Scherp, G., Gudenkauf, S., Meister, D., and Brinkmann, A., "An Orchestration as a Service Infrastructure Using Grid Technologies and WS-BPEL", Service-Oriented Computing, Lecture Notes in Computer Science, 2009, Volume 5900/2009, 301315 .

Hosono, S., Kuno, A., Hasegawa, M., Hara, T., Shimomura, Y., and Arai, T., “A Framework of Co-creating Business Values for IT Services”, 2009 IEEE International Conference on Cloud Computing, September 21-25, 2009, Bangalore, India.

Iyengar, A., Jessani, V. and Chilanti, M., "WebSphere Business Integration Primer: Process Server, BPEL, SCA, and SOA", Book, ISBN :013224831X 9780132248310, 2007.

Kagermann, H., Österle, H., Jordan, J. M., "IT-Driven Business Models: Global Case Studies in Transformation", John Wiley \& Sons, 2011.

Kaplan, B., and Duchon, D., "Combining Qualitative and Quantitative Methods in Information Systems Research: A Case Study", page 571-586, MIS Quarterly, Vol. 12, No. 4, December 1988.

Khajeh-Hosseini A, Greenwood D and Sommerville I, "Cloud Migration: A Case Study of Migrating an Enterprise IT System to IaaS", 3rd IEEE International conference on Cloud Computing, Cloud 2010, 5-10 July 2010; Miami, USA.

Krippaehne, R. C., McCullouch, B. G., and Vanegas, J. A., "Verticak Business Integration Strategies for Construction", Journal of Management in Engineering, 1992.

Lee, C.F., Lee, A.C. and Lee, J. (Editors on behalf of 30 authors),"Handbook of Quantitative Finance and Risk Management, Volume 1", Springer publisher, ISBN 978-0-387-77116-8, 2010.

Longstaff, F.A., and Schwartz, E.S., "Valuing American Options by Simulations: A Simple Least-Squares Approach". Review of Financial Studies, 14, 1, 113-147, 2001.

Moran, D., Vaquero, L.M. and Galan, F., "Elastically Ruling the Cloud: Specifying Application's Behavior in Federated Clouds", 2011 IEEE International Conference on Cloud Computing, 4-9 July 2011, Washington D. C., USA.

Moreno, M. and Navas, J.F., "On the Robustness of Least-Square Monte Carlo (LSM) for Pricing American Derivatives", Journal of Economic Literature Classification, April 2001

Norta, A., "A Hub Architecture for Service Ecosystems", Towards Business-to-Business Automation with an Ontology-Enabled Collaboration Platform, Technical Paper, 2010, University of Helsinki, Finland.

Pajorova E and Hluchy L, "3D visualization the results of complicated Grid and Cloud-based applications", the 14th International Conference on Intelligent Engineering Systems (INES), 5-7 May 2010, Las Palmas, Spain.

Papazoglou, M.P., and Georgakopoulos, D., "Service Oriented Computing", Communications of the ACM, Vol. 46, No. 10, October 2003

Papazoglou M. P. and van den Heuvel, W-J., "Blueprinting the Cloud", IEEE Internet Computing, Vol. 15 No. 6, November/December 2011.

Rebstock, M., Fengel, J. and Paulheim, H., "Ontologies-based business integration", Book, published by Springer, ISBN: 978-3540-75229-5, 2008.

Ribeiro, C. and Webber, N., "Valuing Path Dependent Options in the Variance-Gamma Model by Monte Carlo with a Gamma Bridge", Working Paper, No.02-04, Warwick Business School, September 2002. 
Ribeiro, C. and Webber, N., "Valuing path-dependent options in the variance-gamma model by Monte Carlo with a gamma bridge", The Journal of Computational Finance 7 (2):81-100, 2004.

Rings, T., Caryer, G., Gallop, J., Grabowski, J., Kovacikova, T., Schulz, S. and Stokes-Rees, I., "Grid and Cloud Computing: Opportunities for Integration with the Next Generation Network", Journal of Grid Computing, DOI 10.1007/s10723-009-9132-5, August 2009.

Schubert, H., Jeffery, K. and Neidecker-Lutz, B., "The Future for Cloud Computing: Opportunities for European Cloud Computing Beyond 2010”, Expert Group report, public version 1.0, January 2010.

Sun Microsystems White Paper, "Introduction to Cloud Computing Architecture”, $1^{\text {st }}$ Edition, June 2009.

Trastour, D., Preist, C., and Coleman, D. "Using Semantic Web Technology to Enhance Current Business-to-Business Integration Approaches”, HP Technical Report, November 2003.

Truong, H-L. and Dustdar, S., "Cloud Computing for Small Research Groups in Computational Science and Engineering: Current Status and Outlook", Journal of Computing, SprngLink, 10.1007/s00607-010-0120-1, Vol. 90, September 2010.

Vinoski, S., "Java business integration" IEEE Internet Engineering, Vol. 9, Issue 4, August 2005.

Vojdani, A. F., “Tools for Real-Time Business Integration and Collaboration”, IEEE Transactions on Power Systems, 2003.

Waters, D., “Quantitative Methods for Business” Fourth Edition, Prentice Hall, Financial Times, 2008.

Weinhardt, C., Anandasivam, A., Blau, B., Borissov, N., Meinl T, Michalk, W. and Stober, J., (2009), "Cloud Computing - A Classification, Business Models, and Research Directions”, Journal of Business and Information Systems Engineering, 2009.

Zimmermann, H. G., Neuneier, R. and Grothmann, R., "Active Portfolio-Management based on Error Correction Neural Networks, Working Paper, Siemens AG, 2006.

\section{Appendix}

Codes are written to demonstrate the VG process in the MCM. Table 11 shows the initial part of the code, where key figures such as maturity, volatility and risk free rate are defined. Some part of code algorithm for Least Square Method has been published (Chang et al., 2011 a) and need not shown here.

Table 11: The first part of coding algorithm for Variance-Gamma Processes

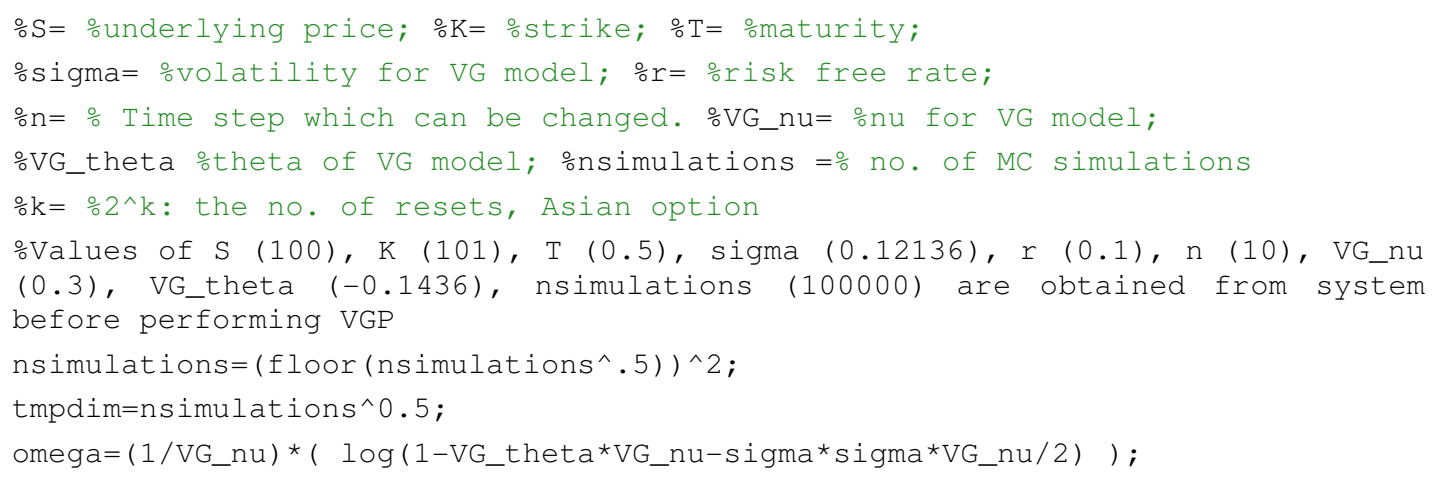

There is a function, gamrnd, in MATLAB to calculate variance gamma model, presented in Table 12.

Table 12: The second part of coding algorithm for Variance-Gamma Processes

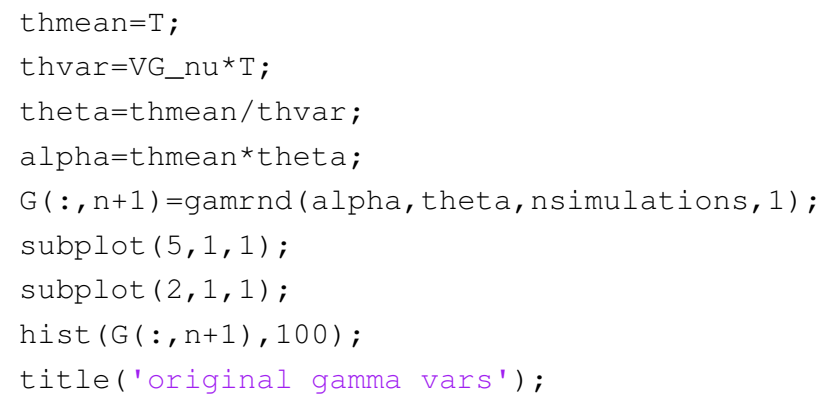


The third part of the code is to calculate stratified gamma sampling presented in Table 13. This includes replicate and tile array (repmat function) and returns the inverse of the gamma cumulative distribution function (cdf) (gaminv function).

Table 13: The third part of coding algorithm showing stratified gamma sampling

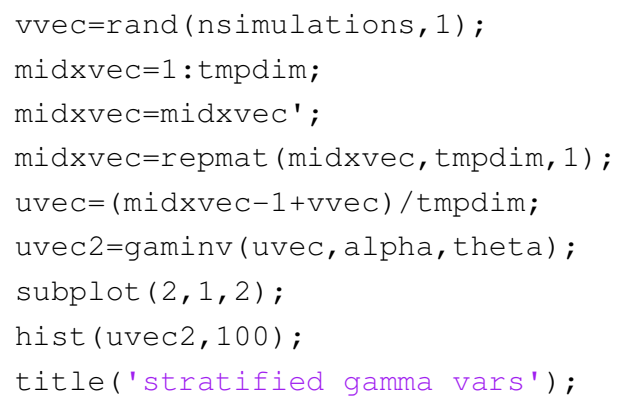

Additional formulations in Table 14 are added to calculate the best calling price based on MCM.

Table 14: The sixth part of the coding algorithm

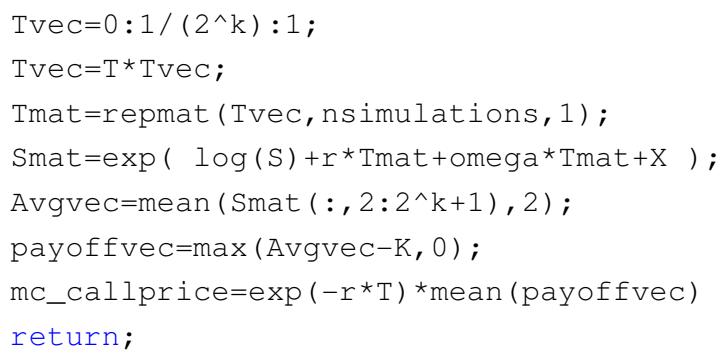

